\title{
DIGESTIBILIDAD DE RACIONES ALTAS EN FIBRA POR EL CERDO CRIOLLO'
}

\author{
R. Jarquín, R. Bressani ${ }^{2}$
}

\section{COMPENDIO}

Se elaboraron raciones isocalóricas e Isoproteicas utilizando una premezcla que contenía $35 \%$ harina torta de soya, $64.6 \%$ maíz y $0.4 \%$ metionina, para las etapas de iniciación crecimiento y desarrollo de cerdos criollos, correspondientes a 8,16 y 26 semanas de edad, que contenían 16,12 y $10 \%$ de proteína, respectivamente. El contenido de material fibroso a evaluarse, Lathyrus, fue de 16.4 y $32.8 \%$ para las tres etapas, sustituyendo su aporte proteico por el de la premezcla, e incrementando almidón. Se presenta información sobre digestibilidad de distintos nutrientes en dietas a base de Lathyrus para cerdos de distintas edades, así corno, resultados obtenidos con cerdos de 8 semanas utilizando Ipomoea. La digestibilidad del contenido celular, aunque disminuyó con el incremento de fibra, mejoró a las 26 semanas de edad. La digestibilidad de la fibra ácido detergente, lignina y energía mejoró con la edad; sin embargo, entre dietas fue a la Inversa. La digestibilidad de celulosa presentó diferencias estadísticas entre dietas. La digestibilidad de la proteína presenta disminución con respecto al contenido de fibra; sin embargo, no muestra diferencias significativas entre dietas ni entre edad de los animales. Los valores de digestibilidad entre Lathyrus e Ipomoea muestran diferencias significativas en las variables fibra ácido detergente, lignina y celulosa en favor de Ipomoea.

Palabras clave adicionales: Alimentación, Lathyrus, Ipomoea.

\section{INTRODUCCIÓN}

Se sabe que el cerdo criollo consume forraje verde como parte de su dieta; sin embargo, se desconoce la eficiencia de digerir la fibra, por lo que se consideró conveniente orientar algunos estudios para conocer la capacidad del cerdo criollo de digerir raciones con un alto contenido de material vegetativo deshidratado, que eleva significativamente el contenido de fibra de la ración.

\section{OBJETIVOS}

1. Establecer la eficiencia digestiva de energía, proteína y fibra del cerdo criollo alimentado con raciones altas en fibras a las 8,16 y 26 semanas de edad.

2. Determinar la influencia del nivel de fibra sobre la digestibilidad de la proteína y de la energía.

\section{MATERIALES Y MÉTODOS}

Los ensayos de digestibilidad se programaron para tres distintas edades que prácticamente corresponden a

\begin{abstract}
A basal mixture containing $35 \%$ soybean meal, $64.6 \%$ corn and $0.4 \%$ methionine was used to formulate isocaloric and isoproteic diets for initiation, growth and finishing periods of development of native pigs, containing 16,12 and $10 \%$ protein to be fed at 8,16 and 26 weeksof age, respectively. Lathyrus-used as the fiber source- was kept constant in the rations at levels of 16.4 and $32.8 \%$ for the three periods studied, reducing the content of the basal mixture in the diets on the basis of the protein contributed by the source of fiber added, and adding starch to maintain protein level constant. Information is presented on the digestibility of the nutrients of the diets for native pigs of 8 weeks of age on diets containing Ipomoea. Digestibility of cellular content decreased with fiber increment, although it improved at 26 weeks of age. Digestibility of acid detergent fiber, lignin and energy improved with age; nevertheless, they decreased between diets. Cellulose digestibility showed statistical differences among diets. Protein digestibility decreased with respect to fiber content, however, no significant differences were detected between age of animals and diets. Digestibility values between Lathyrus show significant differences in acid detergent fiber, lignin and cellulose in favor of Ipomoea.
\end{abstract}

las etapas de iniciación, crecimiento y desarrollo de los cerdos, utilizando raciones de 16, 12 y $10.0 \%$ de contenido proteico respectivamente, acorde a la edad de los animales.

Cada estudio de digestibilidad comprende cuatro días de adaptación a la dieta y cinco días de recolección de heces. Durante el período de recolección se requiere del registro exacto de la cantidad de alimento ingerido y tomar el cuidado de recolectar todas las heces para el registro exacto de su peso. Para determinar cuando iniciar y finalizar la recolección de heces, al inicio del periodo de recolección se les suministra a los cerdos la dieta con un colorante denominado carmín, al aparecer las heces coloreadas se inicia la recolección de las

1Trabajo presentado en la XXXV Reunión del Programa Cooperativo Centroamericano para el Mejoramiento de Cultivos y Animales (PCCMCA), llevado a cabo en San Pedro Sula, Honduras, del 3 al 7 de abril, 1989.

Este trabajo fue financiado con fondos del Programa sobre Mejoramiento de la Productividad del Cerdo Criollo patrocinado por el Centro Internacional de Investigaciones para el Desarrollo -CUD- con sede en Bogotá, Colombia (3-PS5-1010-03).

${ }^{2}$ Científico, División Ciencias Agrícolas y de Alimentos, INCAP, Apartado Postal 1188, Guatemala, Guatemala, C.A. Publicación INCAP E1287.

Publicado en Agronomía Mesoamericana, Vol. 1 (1990). 
mismas. El último día de balance de nuevo se adiciona carmín a la dieta y al aparecer las heces con colorante se finaliza el ensayo.

Para la formulación de las raciones se hizo una premezcla compuesta de $64.6 \%$ de maíz molido, $35 \%$ de harina de torta de soya y $0.4 \%$ de DL metionina. De esta premezcla se tomó la cantidad necesaria para que las dietas a prepararse tuviesen el contenido proteico estimado. Los requerimientos de minerales y vitaminas fueron satisfechos con ingredientes comerciales apropiados, además se utilizó almidón de maíz para alcanzar el $100.0 \%$ de ingredientes en la fórmula.

En el Cuadro 1 se presentan las formulaciones utilizadas en cerdos de 8 semanas de edad. Para las edades correspondientes a 16 y 26 semanas el contenido de material fibroso a evaluarse fue el mismo, reduciendo el contenido proteico de las dietas al porcentaje programado, acorde a la edad de los animales, a expensas de la premezcla soya-maíz, e incrementando el ingrediente almidón. La concentración calórica de las dietas fue similar, para lo cual fue necesario utilizar aceite vegetal.

Las fuentes de fibra utilizadas en la elaboración de las raciones fueron una leguminosa denominada choreque (Lathyrus sativus), y la otra fue la planta denominada campanilla (Ipomoea $\mathrm{sp}$ ). La primera crece exhuberantemente en el altiplano de Guatemala y la segunda en la zona tropical húmeda de los países centroamericanos. Es de hacer notar que la planta de campanilla es un forraje muy apetecido por el cerdo criollo y que el porcinocultor rural lo suministra como parte de la dieta cuando hay disponible.

El cálculo del contenido celular y las determinaciones de paredes celulares, fibra ácido detergente, lignina y celulosa, tanto en dietas como en heces, se hizo empleando los métodos de Van Soest (1967) y Van Soest y Wine (1968). La energía se determinó valiéndose de la bomba calorimétrica (Gallenkamp, 1974), y la proteína por el método de Kjedahl (AOAC, 1984).

Cuadro 1. Formulaciones para cerdos criollos de 8 semanas de edad.

\begin{tabular}{lrrr}
\hline \multicolumn{1}{c}{ Ingredientes } & \multicolumn{3}{c}{$\%$} \\
\hline Premezcla soya-maíz & $\mathbf{1}$ & \multicolumn{1}{c}{$\mathbf{2}$} & \multicolumn{1}{c}{$\mathbf{3}$} \\
Harina de planta deshidratada & 68.60 & 57.80 & 47.00 \\
Vitaminas y elementos menores & ----- & 16.40 & 32.80 \\
Minerales & 0.25 & 0.25 & 0.25 \\
Almidón & 4.00 & 4.00 & 4.00 \\
Aceite & 27.15 & 20.55 & 13.95 \\
& ----- & 1.00 & 2.00 \\
TOTALES & 100.00 & 100.00 & 100.00 \\
Contenido proteico \% & 16.10 & 16.20 & 16.20 \\
Calorías por 100 gramos & 393.00 & 393.00 & 393.00 \\
\hline
\end{tabular}

\section{RESULTADOS EN DIGESTIBILIDAD DE NUTRIENTES}

Los resultados en digestibilidad de los distintos nutrientes se presentan en los Cuadros 2 y 3 , interpretándose la información en la forma siguiente:

1. La digestibilidad del contenido celular y paredes celulares disminuye con respecto al incremento de fibra en las dietas, así como también con respecto

Cuadro 2. Digestibilidad de los distintos componentes de las dietas.

\begin{tabular}{|c|c|c|c|c|c|c|}
\hline $\begin{array}{l}\text { Edad cerdos } \\
\text { (semanas) }\end{array}$ & Dietas & $\begin{array}{l}\text { Conte- } \\
\text { nido } \\
\text { celular }\end{array}$ & $\begin{array}{c}\text { Paredes } \\
\text { celu- } \\
\text { lares }\end{array}$ & $\begin{array}{c}\text { Fibra } \\
\text { ácido } \\
\text { det. }\end{array}$ & $\begin{array}{l}\text { Lig- } \\
\text { nina }\end{array}$ & $\begin{array}{l}\text { Celu- } \\
\text { losa }\end{array}$ \\
\hline \multirow{3}{*}{8} & $1 *$ & 93.5 & 76.6 & 68.6 & 77.7 & 69.6 \\
\hline & $2^{*}$ & 90.0 & 62.1 & 52.6 & 55.2 & 53.4 \\
\hline & $3 *$ & 85.0 & 59.0 & 44.2 & 42.5 & 45.5 \\
\hline \multirow{3}{*}{16} & $1^{*}$ & 93.3 & 74.2 & 75.7 & 87.3 & 77.1 \\
\hline & $2^{*}$ & 85.3 & 53.0 & 53.4 & 63.4 & 47.8 \\
\hline & $3 *$ & 82.2 & 52.9 & 56.0 & 59.0 & 52.9 \\
\hline \multirow{3}{*}{26} & $1^{*}$ & 93.7 & 63.2 & 72.6 & 84.5 & 70.6 \\
\hline & $2 *$ & 90.8 & 43.3 & 54.0 & 60.3 & 52.7 \\
\hline & $3^{*}$ & 88.8 & 45.4 & 49.3 & 47.4 & 52.0 \\
\hline \multirow{3}{*}{8} & $1 * *$ & 93.6 & 80.3 & 82.7 & 88.3 & 82.6 \\
\hline & $2 * *$ & 89.8 & 67.0 & 68.8 & 71.7 & 69.0 \\
\hline & $3 * *$ & 82.7 & 51.4 & 56.2 & 52.7 & 60.2 \\
\hline
\end{tabular}

* Dietas a base de choreque

** Dietas a base de campanilla

NOTA: Cada grupo experimental estuvo conformado por ocho lechones.

Cuadro 3. Digestibilidad de energía y proteína de las Dietas

\begin{tabular}{|c|c|c|c|}
\hline $\begin{array}{l}\text { Edad cerdos } \\
\text { (semanas) }\end{array}$ & Dietas & Energía & Proteína \\
\hline 8 & $\begin{array}{l}1 * \\
2^{*} \\
3^{*}\end{array}$ & $\begin{array}{l}91.8 \\
84.4 \\
78.4\end{array}$ & $\begin{array}{l}86.9 \\
81.4 \\
77.0\end{array}$ \\
\hline 16 & $\begin{array}{l}1^{*} \\
2^{*} \\
3^{*}\end{array}$ & $\begin{array}{l}94.6 \\
85.1 \\
82.3\end{array}$ & $\begin{array}{l}88.8 \\
81.0 \\
77.2\end{array}$ \\
\hline 26 & $\begin{array}{l}1^{*} \\
2^{*} \\
3^{*}\end{array}$ & $\begin{array}{l}93.3 \\
86.6 \\
84.6\end{array}$ & $\begin{array}{l}86.2 \\
80.8 \\
76.2\end{array}$ \\
\hline 8 & $\begin{array}{l}1^{* *} \\
2^{* *} \\
3^{* *}\end{array}$ & $\begin{array}{l}93.7 \\
87.3 \\
78.4\end{array}$ & $\begin{array}{l}88.3 \\
81.9 \\
69.8\end{array}$ \\
\hline
\end{tabular}


a la edad de los cerdos, aunque se detecta una mejor digestibilidad del contenido celular a las 26 semanas de edad.

2. La digestibilidad de la fibra ácido detergente y lignina tiende a mejorar en relación al incremento de edad de los cerdos; sin embargo, entre dietas el fenómeno es a la inversa.

3. La digestibilidad de la celulosa presenta valores bastante similares entre las distintas edades de los cerdos; sin embargo entre dietas, el análisis estadístico revela diferencias significativas.

4. La digestibilidad de la energía tiende a aumentar con relación a la edad de los cerdos; sin embargo, entre dietas el fenómeno es a la inversa.

5. La digestibilidad de la proteína presenta una disminución con respecto a las dietas, valores entre los cuales no existen diferencias estadísticas significativas, según el análisis de varianza realizado; asimismo, los valores de digestibilidad de proteína con respecto a la edad de los cerdos no presentan significancia estadística.

En relación a la comparación más importante, que se refiere a las diferencias en digestibilidad de los materiales Lathyrus e Ipomoea, sólo se tiene información en cerdos de 8 semanas de edad, detectándose que para las variables, fibra ácido detergente, lignina y celulosa existen diferencias significativas, siendo más digeribles en estos parámetros.

En el Cuadro 4 se muestra el contenido de aminoácidos esenciales del choreque y campanilla; ambas harinas deshidratadas superan al maíz en su composición aminoacídica, por lo tanto se espera que el follaje deshidratado de cualquiera de las dos plantas contribuirá significativamente a la complementación del maíz o maicillo.

Como ejemplo de lo expuesto se presenta información en el Cuadro 5 sobre la contribución de aminoácidos de una mezcla de $32.0 \%$ de choreque y $68.0 \%$ de maíz para cerdos de 20 a $35 \mathrm{~kg}$ de peso vivo.

Analizando el Cuadro 5 se puede predecir que el requerimiento del triptófano puede ser cubierto por el choreque, del cual no se tiene análisis. La premezcla de $32.0 \%$ choreque y $68.0 \%$ maíz es limitante en metionina y lisina. El primer aminoácido limitantes es producido sintéticamente a precio cómodo en el mercado local. El segundo aminoácido limitante tiene que ser incluido en la dicta, utilizando un ingrediente que eleve el contenido proteico de $11.0 \%$ a $14,0 \%$, que sería el requerimiento para cerdos de ese peso, lo que se podría obte- ner agregando un $8.0 \%$ de soya cubriendo en dicha forma el requerimiento proteico y del aminoácido lisina. El solo hecho de emplear un buen forraje verde en combinación con maicillo, mejorará significativamente la conversión alimenticia en el cerdo criollo, derivándose consecuentemente implicaciones económicas beneficiosas para el porcinocultor rural.

Cuadro 4. Contenido de aminoácidos esenciales de las plantas en estudio comparadas con el maíz.

\begin{tabular}{lccc}
\hline Aminoácido & Choreque & Campanilla & Maíz \\
\hline Arginina & 1.08 & 0.92 & 0.45 \\
Histidina & 0.34 & 0.24 & 0,18 \\
Isoleucina & 0,75 & 0.65 & 0.45 \\
Leucina & 1.09 & 0.92 & 0.99 \\
Metionina & 0.39 & 0.29 & 0.09 \\
Fenilalanina & 0.62 & 0.48 & 0.45 \\
Treonina & 0.65 & 0.54 & 0.36 \\
Triptófano & & -0.75 & 0.09 \\
Valina & 0.93 & 034 & 0.36 \\
Lisina & 0.88 & & 0,18 \\
\hline
\end{tabular}

Cuadro 5. Aporte de aminoácidos de una mezcla $32 \%$ choreque y $68 \%$ maíz, para cerdos de 20 a $35 \mathrm{~kg}$ de peso vivo

\begin{tabular}{lcccc}
\hline $\begin{array}{c}\text { Aminoácido } \\
\text { esencial }\end{array}$ & $\begin{array}{c}\text { Choreque } \\
\mathbf{3 2 \%}\end{array}$ & $\begin{array}{c}\text { Maíz } \\
\mathbf{6 8 \%}\end{array}$ & $\begin{array}{c}\text { Aporte A.A. } \\
\text { Ingredientes Cero 2.0 a 35 kg } \\
\text { \% }\end{array}$ & $\begin{array}{c}\text { \% } \\
\text { Requeniento }\end{array}$ \\
\hline Arginina & 0,35 & 0.30 & 0.65 & 0.20 \\
Histidina & 0.10 & 0,12 & 0.22 & 0.18 \\
Isoleucina & 0.24 & 0.30 & 0.54 & 0.50 \\
Leucina & 0.35 & 0.67 & 1.02 & 0.60 \\
Metionina & 0.12 & 0.20 & 0.32 & 0.50 \\
Fenilalania & 0.20 & 0.31 & 0.51 & 0.50 \\
Treonina & 0.21 & 0.24 & 0.45 & 0.45 \\
Triptófano & ---- & 0.09 & 0.09 & 0.13 \\
Valina & 0.29 & 0.25 & 0.54 & 0.50 \\
Lisina & 0.28 & 0.12 & 0.40 & 0.70 \\
\hline
\end{tabular}

\section{BIBLIOGRAFIA}

AOAC. 1984. Official methods of analysis of the Association of Official Analytical Chemists. 14th. ed. Arlingion, VA,, The Association, p. 16

GALLENKAMP, A. 1974. Gallenkamp ballistic bomb calorimeter CBB370370 (Operation Manual London), London, p. 3-7.

VAN SOEST, P.J. 1967. Development of a comprehensive system of feed analysis and its application to forages. 1. Animal $\mathrm{Se}_{i}$ 26:119-128.

; WINE, R.H. 1968. Determination of lignin and cellulose in acid detergent fiber with permanganate. JAOAC. 51:780-785 